\title{
TRTaKadeMi
}

ISSN 2149-9446 | Cilt 06 | Sayı 12 | Mayıs 2021 | Dijital Hayat ve Etik

\section{Öğretmen Adaylarının Dijital Etik Düzeylerinin Bazı Değişkenler Açısından İncelenmesi'}

\author{
Özkan ÖZBAY* - Uğur DOĞAN** \\ Esma YILDIZ*** - Süleyman Sadi SEFEROĞLU****
}

\begin{abstract}
Öz
Bilişim teknolojileri insanlara birçok firsat sunmakla birlikte önümüzdeki yıllarda etkileri daha da belirgin hâle gelebilecek bazı etik sorunları da ortaya çıkarmaktadır. Bu nedenle gelecek nesilleri yarına hazırlamada önemli bir rol üstlenen öğretmenlerin, dijital etik konusunda yeterli bilgiye sahip, bilişim teknolojilerini etik kullanan iyi birer dijital vatandaş olmaları gerekmektedir. Bu araştırmada öğretmen adaylarııı bilişim teknolojilerini etik kullanım düzeyleri bazı değişkenler açısından incelenmiştir. Araştırma kesitsel tarama modelinde desenlenmiştir. Araştırmanın çalışma grubunu farklı devlet üniversitelerinin eğitim fakültelerinde öğrenim gören toplam 221 öğretmen adayı oluşturmaktadır. Araştırmada veri toplama aracı olarak "Kişisel Bilgi Formu" ve "Bilgi ve Illetişim Teknolojileri Etiği Ölçeği" kullanıımıştr. Verilerin analizi sonucunda öğretmen adaylarının bilişim teknolojilerini etik kullanım düzeylerinin; cinsiyet, bölüm, internet kullanma becerisi, bilişim etiğine ilişkin daha önce ders, kurs veya seminere katılma durumu, bilişim suçları ve cezalarına ilişkin bilgi düzeyine göre istatistiksel olarak anlamlı bir farklılık gösterdiği tespit edilmiştir. Araştırma sonucuna göre öğretmen adaylarının bilişim teknolojilerini etik kullanım düzeylerinin yüksek olduğu sonucuna ulaşılmıştır.
\end{abstract}

Anahtar Kelimeler: Bilgi ve Iletişim Teknolojileri, Dijital Etik, Etik Olmayan Davranışlar, Öğretmen Adayları, Bilgisayar Etiği

*Öğr. Görevlisi, Artvin Çoruh Ünv., Uzaktan Eğitim Uygulama ve Araştırma Merkezi, ozkanozbay@hacettepe.edu.tr

**Öğr. Görevlisi, Sakarya Uyg. Bilimler Ünv., Uzaktan Eğitim Uygulama ve Araştırma Merkezi, ugurdogan2626@gmail.com

*** Arş. Görevlisi, Amasya Ünv., Eğt. Fakültesi, Bilgisayar ve Öğretim Teknolojileri Eğitimi Bölümü, esma.yildiz@amasya.edu.tr

**** Prof. Dr., Hacettepe Ünv., Eğt. Fakültesi, Bilgisayar ve Öğretim Teknolojileri Eğitimi Bölümü, sadi@hacettepe.edu.tr

${ }^{1}$ Bu çalışmanın bir kısmı 30 Ekim-01 Kasım 2019 tarihleri arasında düzenlenen 7. Uluslararası Öğretim

Teknolojileri ve Öğretmen Eğitimi Sempozyumu'nda sözlü bildiri olarak sunulmuştur.

Araştırma Makalesi

Geliş Tarihi: 10.04 .2021

Kabul Tarihi: 24.05.2021

ORCID ID: 0000-0001-7754-2594

DOI: $10.37679 /$ trta.913015

ORCID ID: 0000-0002-1729-6763

ORCID ID: 0000-0002-0916-9924

ORCID ID: 0000-0002-5010-484X 


\title{
TRTAKaDeMi
}

ISSN 2149-9446 | Volume 06 | Issue 12 | May 2021 |Digital Life and Ethics

\section{Investigation of Pre-service Teachers' Digital Ethics Levels in Terms of Some Variables}

\author{
Özkan ÖZBAY - Uğur DOĞAN \\ Esma YILDIZ - Süleyman Sadi SEFEROĞLU
}

\begin{abstract}
Information technologies offer many opportunities to people. However, they cause some ethical problems whose impacts may become more apparent in the coming years. Thus teachers, who play a key role in preparing the posterity to the future, are expected to be good digital citizens who have adequate information on digital ethics and are competent in the ethical use of information technologies. In this research, pre-service teachers' ethical use levels of information technologies were examined in terms of some variables. The research was designed in a cross-sectional survey. The study group comprised a total of 221 pre-service teachers studying in faculties of education in different state universities. In the research, the "Personal Information Form" and "Information and Communication Technologies Ethics Scale" were used as data collection tools. As a result of data analysis, it was determined that the preservice teachers' ethical use level of information technologies showed a statistically significant difference according to their gender, department, the skill of using the internet, state of having previously participated in a course or seminar regarding digital ethics, and their knowledge level of cyber-crimes and law enforcement. According to the research result, it was concluded that the pre-service teachers had a high ethical use level of information technologies.
\end{abstract}

Keywords: Information and Communication Technologies, Digital Ethics, Unethical Behavior, Pre-Service Teachers, Computer Ethics

Research Paper

Recieved: 10.04 .2021

Accepted: 24.05.2021 


\section{Giriş}

Bilişim teknolojilerinin yayılmasının getirdiği sosyal, kültürel, ekonomik ve politik değişimler hayatımızın her alanını etkileyerek iletişimden alışverişe, çalışma şeklinden öğrenmeye kadar birçok alışkanlığımızın değişmesine yol açmıştır (Meyers, Erickson ve Small, 2013). Bu değişim beraberinde dijital vatandaşlık, dijital yerli, dijital göçmen, dijital etik, dijital okuryazarlık ve dijital uçurum gibi toplum yaşamında önemli hâle gelen bazı kavramları ortaya çıkarmıştı (Buchholz, DeHart ve Moorman, 2020; Chen, Mirpuri, Rao ve Law, 2021; Gilster, 1997; Mossberger, Tolbert ve McNeal, 2007; NTAl, 1999; Prensky, 2001). Bu bağlamda dijital çağa ayak uydurmada önemli hâle gelen bu kavramların ileride daha da önem kazanacak olmasından dolayı bireyler tarafindan en iyi biçimde bilinmesi ve özümsenmesi gerekmektedir.

Toplumun yapısal unsurlarını etkileyen, temel ve geri dönülemez değişimlere yol açan yeni teknolojilerin hayatımıza getirdiği dijitalleşmeden dolayı öncelikle dijital vatandaşlık becerilerinin bireylere kazandırılması gerekmektedir (Gazi, 2016; Hollandsworth, Donovan ve Welch, 2017). Dijital vatandaşlık; birbirine bağlı dijital dünyada yaşayan, öğrenme, çalışma hak ve sorumluluklarını bilen, güvenli, yasal ve etik yollarla hareket edip model olan vatandaş olarak tanımlanmaktadır (ISTE, 2016). Dijital vatandaşlık kavramı; dijital erişim, dijital ticaret, dijital iletişim, dijital okuryazarlık, dijital görgü, dijital kanun, dijital haklar ve sorumluluklar, dijital sağlık ve dijital güvenlik olmak üzere 9 alt boyutu da beraberinde getirmektedir (Ribble, 2015). Ancak bu 9 alt boyutun yanı sıra dijital vatandaşlar olarak bilişim teknolojilerden en iyi şekilde yararlanılabilmesi, yeni teknolojilerin geliştirilmesine, uygulanmasına ve denetlenmesine rehberlik edebilecek etik ilkelerle mümkündür. Bu nedenle bilişim teknolojilerinin etik kullanımının da dikkate alınması gerekmektedir.

Bilişim teknolojilerinin kullanımının her açıdan doğru işlediğine duyulan güven toplum için zararlı olabilecek bazı sonuçların ön görülememesine neden olmaktadır. Hiçbir teknolojinin bazı sapmalar sergilemeden mükemmel tasarlanması mümkün değildir (Johnson ve Miller, 2009; Marshall, 1999; Moor, 2004). Bilişim teknolojilerinin kullanımında ise bu sapmaların başında etik sorunlar gelmektedir. Bu nedenle bilişim teknolojilerinin etik açıdan toplum üzerindeki olumsuz etkisini ortadan kaldırmaya yönelik dijital etik ilkelerine intiyaç duyulmaktadır. Ancak diğer alanlara kıyasla bilişim teknolojilerinin doğası gereği sürekli olarak yeni gelişmelere ayak uydurması ve yeni değerlerin ortaya çıkarılması gerektiğinden etik ilkelerin belirlenmesi daha güçtür. Dijital hayattaki etik anlayışımızın gerçek hayattan farklı ve gerçek hayatla benzer olan yanlarının ortaya çıkarılması, yeni etik sorunların varlığına yönelik yeni etik çözümlerin geliştirilmesini gerektirmektedir (Friedman, 1997; Mason, 1986; Moor, 2005). Bu nedenle dijital etik ilkeler, bilişim teknolojilerinin 
topluma olan zararlarını azaltırken faydalarını koruyacak biçimde belirlenmelidir. Alanyazında yer alan çalışmalar dijital etik ilkelerinin oluşturulmasında genel olarak fikri mülkiyet, gizlilik, erişim ve doğruluk konularına odaklanmışlardır (Floridi, 2001; Freeman ve Peace, 2005; Mason, 1986; Morgan ve Morgan, 2008). Bu çalışmaların yanı sıra bilgisayarların toplumsal etkileri, güvenlik, kalite, bilgi ve ağ doğruluğu konularına da odaklanan çalışmalar mevcuttur (Dedeoğlu, 2006; Johnson, 1985, Namlu ve Odabaşı, 2007).

Günümüz dünyasında bilişim teknolojilerini etkin bir şekilde kullanan her bireyin dijital etik ilkelerine uymasının 21. yüzyılın temel becerilerinden biri olduğu ifade edilmektedir (Mason, 1986; Moor, 1985; Snyder, 2012). Türkiye İstatistik Kurumu'nun (TÜIK) 2020 yılında gerçekleştirmiş olduğu 16-74 yaş grubundaki bireylerin "bilişim teknolojileri kullanım araştırması" incelendiğinde, internet kullanan bireylerin interneti kişisel kullanma amaçlarının; e-posta gönderme/alma, internet üzerinden telefon veya webcam ile görüşme, sosyal medya üzerinde profil oluşturma, mesaj gönderme, fotoğraf vb. içerik paylaşma, mesajlaşma, çevrim içi haber okuma, sağlıkla ilgili bilgi arama, mal ve hizmetler hakkında bilgi arama olduğu ifade edilmiştir. Bunlara, web siteleri aracılığıyla görüş paylaşma, toplumsal veya siyasal bir konuda çevrim içi bir oylamaya katılma, iş arama ya da iş başvurusu yapma, kendi oluşturdukları metin, fotoğraf, müzik, video, yazılım vb. içerikleri herhangi bir web sitesine paylaşmak üzere yükleme, müzik dinleme, mal veya hizmet satışı ve internet bankacılığı ilave olarak belirtilebilir. TÜiK' in (2020) “Hanelerde bilişim teknolojileri kullanımı araştırmasında" ise internet kullanımının ülke genelinde \%79’a yükseldiği tespit edilmiştir. Tüik araştırmaları da dikkate alındığında dijital hayatın etkin birer üyesi olan bireylerin bilişim teknolojilerinin sahip olduğu tüm avantajlarından en iyi şekilde yararlanmak istedikleri görülmektedir. Ancak bilişim teknolojileri topluma birçok fayda sağlıyor olsa da asıl odaklanılması gereken nokta bilişim teknolojilerinin topluma zarar vermeyecek biçimde etik kullanılmasıdır (Moor, 1985; Moor, 2005). Bu nedenle bireylere bilişim teknolojilerini kullanırken dijital etik ilkelerine uygun davranışlar sergilemelerini sağlayacak etik duyarlılık ve farkındalığın kazandırıması gerekmektedir (Moor, 1985).

Toplumun şekillenmesinde önemli bir yere sahip olan öğretmenlerin bilişim teknolojilerini kullanırken güvenilir bilgi ve kaynaklara ulaşabilen, doğru biçimde alıntı yapabilen, fikri mülkiyetleri koruyabilen, kendi dijital kaynaklarını üretebilen, başkalarının kültürel farklılıkları ve haklarına saygı gösterebilen dijital etik ilkelerini benimsemiş iyi birer eğitimci olmaları beklenmektedir (Instefjord ve Munthe, 2017; Kelentrić, Helland ve Arstorp, 2017; Lund, Furberg, Bakken ve Engelien, 2014). Alanyazında yapılan çalışmalar, öğretmen adaylarının dijital etiğe ilişkin yeterlilikle- 
rinin geliştirilmesi gerektiğini, dijital etiğin öğretmen eğitiminde dijital yeterlilikler kapsamında geliştirilebilecek bir alan olduğunu ve dijital etik eğitiminin sadece öğretmen eğitiminde değil genel olarak eğitimin her kademesinde bir eksiklik olduğunu belirtmektedir (Kuzu, 2009; Luke, 2018; Pérez Garcias ve Marín, 2016).

\subsection{Araştırmanın Amacı ve Önemi}

Hayatın her aşamasında bilişim teknolojilerini kullanan bireylerin, birer dijital vatandaş olarak bilişim teknolojilerini dijital vatandaşığın gerektirdiği ölçüde kullanma yetkinliklerine sahip olması gerekmektedir (Ribble, Bailey ve Ross, 2004). Bu açıdan öğrenme ve öğretme sürecinin temel ögelerinden biri olan öğretmenlere, öğrencilere bilişim teknolojilerinin doğru ve etik kullanılmasının aşılanabilmesi konusunda önemli sorumluluklar düşmektedir. Gelecek nesli dijital çağa hazırlaması beklenen öğretmenlerin uygun öğrenme ortamlarını tasarlayıp geliştirebilmeleri ve dijital vatandaşıkta öğrencilere rol model olmaları beklenmektedir (ISTE, 2017).

Bilişim teknolojileriyle yoğun bir etkileşim içinde bulunan günümüz öğrencilerinin, dijital etiğe ilişkin yeterliklerinin erken yaşlardan itibaren geliştirilmesine yönelik çabalar gelecekteki olası problemleri de önleyebilecektir (Çelen ve Seferoğlu, 2016; Sivin ve Bialo, 1992). Bu bağlamda gelecekte yeni nesli yetiştirecek olan öğretmen adaylarının bilişim teknolojilerinin etik kullanımı konusundaki nitelikleri önem kazanmaktadır. Alanyazında öğretmen adaylarının bilişim teknolojilerini etik kullanım düzeylerini araştıran çalışmaların az olması bu çalışmanın önemini artırmaktadır.

Bu doğrultuda bu araştırmanın amacı öğretmen adaylarının bilişim teknolojilerini etik kullanım düzeylerini belirlemektir. Bu amaçla öğretmen adaylarının bilişim teknolojilerini etik kullanım düzeyleri çeşitli değişkenler açısından incelenmiştir. Bu amaca ulaşmak için aşağıdaki sorulara yanıt aranmıştr:

1. Öğretmen adaylarının bilişim teknolojilerini etik kullanım düzeyleri nasııdır?

2. Öğretmen adaylarının bilişim teknolojilerini etik kullanım düzeyleri cinsiyete göre farklılaşmakta mıdır?

3. Öğretmen adaylarının bilişim teknolojilerini etik kullanım düzeyleri yaşa göre farklılaşmakta mıdır?

4. Öğretmen adaylarının bilişim teknolojilerini etik kullanım düzeyleri bölüme göre farklılaşmakta mıdır?

5. Öğretmen adaylarının bilişim teknolojilerini etik kullanım düzeyleri internet kullanma sıklı̆ı̆na göre farkıılaşmakta mıdır? 
6. Öğretmen adaylarının bilişim teknolojilerini etik kullanım düzeyleri internet kullanma becerisine göre farklılaşmakta mıdır?

7. Öğretmen adaylarının bilişim teknolojilerini etik kullanım düzeyleri bilişim etiğine ilişkin daha önce ders, kurs veya seminere katılma durumuna göre farklılaşmakta mıdır?

8. Öğretmen adaylarının bilişim teknolojilerini etik kullanım düzeyleri bilişim suçları ve cezalarına ilişkin bilgi düzeyine göre farklılaşmakta mıdır?

\section{Yöntem}

Öğretmen adaylarının bilişim teknolojilerini etik kullanım düzeylerini belirlenen değişkenler açısından incelemeyi amaçlayan bu araştırma kesitsel tarama modelinde desenlenmiştir. Kesitsel tarama araştırmaları; belirli bir örneklemde, belirli bir zamanda, belirli bir konunun sıklığının veya düzeyinin belirlenmesinde kullanılır (Fraenkel, Wallen ve Hyun, 2011). Bu araştırmada öğretmen adaylarının bilişim teknolojilerini etik kullanım düzeyleri; cinsiyet, yaş, bölüm, internet kullanma beceri ve sıklığı, bilişim etiğine ilişkin daha önce ders, kurs veya seminere katılma durumu, bilişim suç ve cezalarına ilişkin bilgi düzeyi değişkenleri açısından incelenmiştir.

\section{1. Çalışma Grubu}

Bu araştırmanın çalışma grubunu farklı devlet üniversitelerinin eğitim fakültelerinde öğrenim görmekte olan öğretmen adayları oluşturmaktadır. Çalışmada 167'si kadın (\%75.6), 54'ü erkek (\%24.4) olmak üzere toplam 221 öğretmen adayına ulaşılmıştır. Katılımcılara çevrim içi ortam üzerinden ulaşılmıştır. Bu süreçte çeşitli eğitim fakültelerinden öğretim elemanlarına veri toplama formları yollanarak öğretmen adaylarına bu formları doldurtmaları konusunda destek talep edilmiştir. Katılımın gönüllülük esasına dayandığı araştırmada çalışma grubunda yer alan öğretmen adaylarına ilişkin dağılımlar Tablo 1'deki gibidir.

Tablo 1. Katılımcıların Cinsiyet ve Öğrenim Gördükleri Bölüme Göre Dağılımları

\begin{tabular}{|c|c|c|c|c|c|c|}
\hline \multirow{3}{*}{ Kattlımcıların Bölümleri } & \multicolumn{4}{|c|}{ Cinsiyet } & \multirow{2}{*}{\multicolumn{2}{|c|}{ Toplam }} \\
\hline & \multicolumn{2}{|c|}{ Erkek } & \multicolumn{2}{|c|}{ Kadın } & & \\
\hline & $f$ & $\%$ & f & $\%$ & f & $\%$ \\
\hline Bilgisayar ve Öğretim Teknolojileri Eğitimi & 8 & 14.8 & 13 & 7.8 & 21 & 9.50 \\
\hline Fen Bilgisi Öğretmenliği & 13 & 24.1 & 38 & 22.7 & 51 & 23.09 \\
\hline ilköğretim Matematik Öğretmenliği & 4 & 7.4 & 17 & 10.2 & 21 & 9.50 \\
\hline
\end{tabular}




\begin{tabular}{|c|c|c|c|c|c|c|}
\hline Sınıf Öğretmenliği & 10 & 18.5 & 55 & 32.9 & 65 & 29.41 \\
\hline Sosyal Bilgiler Öğretmenliği & 9 & 16.7 & 13 & 7.8 & 22 & 9.95 \\
\hline Türkçe Öğretmenliği & 10 & 18.5 & 31 & 18.6 & 41 & 18.55 \\
\hline Toplam & 54 & 100.0 & 167 & 100.0 & 221 & 100.0 \\
\hline
\end{tabular}

Araştırmaya katılan 221 öğretmen adayından 21'i Bilgisayar ve Öğretim Teknolojileri Eğitimi (BÖTE) (\%9.50), 51'i Fen Bilgisi Öğretmenliği (\%23.09), 21'i illköğretim Matematik Öğretmenliği (\%9.50), 65’i Sınıf Öğretmenliği (\%29.41), 22’ i Sosyal Bilgiler Öğretmenliği (\%9.95), 41'i Türkçe Öğretmenliği (\%18.55) bölümünde öğrenim görmektedir.

\subsection{Verilerin Toplanması}

$\mathrm{Bu}$ araştırmada iki adet veri toplama aracı kullanılmıştır. Illk veri toplama aracı araştırmacılar tarafindan hazırlanan "Kişisel Bilgi Formu"dur. Ikinci veri toplama aracı ise "Bilgi ve İletişim Teknolojileri Etiği Ölçeği" başlıklı bir ölçektir. Veri toplama araçları araştırmacılar tarafindan Google Formlar kullanılarak oluşturulmuştur. Oluşturulan form eğitim fakültelerinde derse giren öğretim elemanlarına ulaştırılmış ve öğretim elemanlarının gözetiminde öğrencilerin bilgisayar veya cep telefonu aracılığıyla doldurmaları sağlanmıştır.

Kişisel Bilgi Formu: Bu form, öğretmen adaylarının; cinsiyet, yaş, üniversite, fakülte/yüksekokul, bölüm, sınıf, internet kullanma becerisi, günlük internet kullanma sıklığı, bilişim etiğine ilişkin kurs, ders veya seminer alıp almadığı, bilişim suçları ve cezalarına ilişkin bilgi düzeyinin sorulduğu 10 maddeden oluşmaktadır.

Bilgi ve İletişim Teknolojileri Etiği Ölçeği: Öğretmen adaylarının bilişim teknolojilerini etik kullanım düzeylerini belirlemek amacıyla Torun (2014) tarafindan geliştirilen Bilgi ve İletişim Teknolojileri (BIT) kullanımında karşılaşılan etik olmayan davranışların ortaya çıkarılmaya çalışıldığı "Bilgi ve Illetişim Teknolojileri Etiği Ölçeği” kullanılmıştır. Bu ölçek (1) ile (7) arasında değişen yedili likert tipinde hazırlanmış olup 28 maddeden oluşmaktadır. Ölçekte yer verilen maddelerin her biri Bіт kullanımında sergilenen etik olmayan davranışları ifade etmektedir. Bu davranışlar, ilgili alanyazın incelenerek (1) Doğruluk, (2) Bilgi ve İletişim Teknolojilerinin Toplumsal Etkileri, (3) Telif Hakları ve (4) Güven olmak üzere dört boyut altında yer almaktadır. Torun (2014) tarafindan ölçeğin güvenirliği için kullanılan Cronbach Alfa değeri tüm ölçek için 0.937 olarak hesaplanmıştır. Bu araştırmada ise ölçeğin güvenirliği için kullanılan Cronbach Alfa değeri tüm ölçek için 0.740 olarak hesaplanmıştır. Ölçekten alınabilecek en düşük puan 28 , en yüksek puan 
ise 196 'dır. Ölçekten alınan puan arttkça bilişim teknolojilerinin etik dışı kullanımı da artmaktadır.

\subsection{Verilerin Analizi}

$\mathrm{Bu}$ araşttrmada elde edilen veriler SPSS-21 paket programı kullanılarak analiz edilmiştir. Veriler tanımlayıcı ve çıkarımsal istatistik kapsamında ele alınmıştır. Öğretmen adaylarının cinsiyet, yaş, bölüm, internet kullanma sıklığı, internet kullanma becerisi, bilişim etiğine ilişkin daha önce ders, kurs veya seminere katılma durumu, bilişim suçları ve cezalarına ilişkin bilgi düzeyi bağımsız değişkenleri ile bilişim teknolojilerini etik kullanma düzeyleri bağımlı değişkenine ilişkin ortalama puan ve standart sapmalar dikkate alınarak bağımsız örneklemler t-testi, tek yönlü varyans analizi (ANOVA) Mann-Whitney $\mathrm{U}$ testi ve Kruskall-Wallis $\mathrm{H}$ testi yapılmıştır. Analizler yapılmadan önce ilgili analizlerin varsayımları test edilmiştir. İstatistiksel anlamlılık düzeyi $\mathrm{p}<0.05$ olarak kabul edilmiştir.

\section{Bulgular}

Bulgular bu araştırmanın amacı doğrultusunda belirlenen araştırma sorularını ayrı ayrı cevaplandırılacak şekilde sunulmuştur. Bu bağlamda aşağıda her bir araştırma sorusu ile ilgili olarak istatistiksel tekniklerle yapılan analizler sonucunda elde edilen bulgulara yer verilmiştir.

\section{1. Öğretmen Adaylarının Bilişim Teknolojilerini Etik Kullanım Düzeyleri}

Bu araştırmanın ilk araştırma sorusu "Öğretmen adaylarının bilişim teknolojilerini etik kullanım düzeyleri nasıldır?" şeklinde belirlenmiştir. Bu soruya yanıt bulmak için 221 öğretmen adayının Bilgi ve İletişim Teknolojileri Etiği Ölçeğine verdikleri cevaplar betimsel olarak incelenmiştir. Bu soruya ilişkin analiz sonuçları Tablo 2'de sunulmuştur.

Tablo 2. Ölçek Maddelerinin Ortalama ve Standart Sapma Değerlerinin Dağılımı

\begin{tabular}{|c|c|c|}
\hline Bilgi ve İletişim Teknolojileri Etiği Ölçeğinin Maddeleri & $\overline{\mathbf{X}}$ & SS \\
\hline 1. Kopya yazılım kullanmak & 1.56 & 1.10 \\
\hline 2. Lisans/şifre kırma programları kullanmak & 1.52 & 1.20 \\
\hline 3. Ödev hazırlayan sitelere ödev yaptırmak & 1.74 & 1.30 \\
\hline 4. Lisanslı ürünleri sahibinden izin almadan kullanmak & 1.38 & 0.86 \\
\hline 5. Korsan CD ve DVD çoğaltıp satmak & 1.21 & 0.68 \\
\hline 6. İnternet üzerinden müzik dosyaları indirmek, çoğaltmak ve dağıtmak & 2.76 & 1.96 \\
\hline 7. Interneti gerçek dışı bilgileri yaymak için kullanmak & 1.08 & 0.39 \\
\hline 8. İnternet bankacılığı kullanan kişilerin hesap bilgilerini ele geçirmeye çalışmak & 1.05 & 0.29 \\
\hline
\end{tabular}


9. Sanal ortamda insanları maddi olarak zor duruma sokmaya çalışmak

10. Web sitesi yöneticilerinin kayıtlı kullanıcı bilgilerini izinsiz olarak başkalarına dağıtması

11. Alınan bir e-postayı sahibinden izinsiz genele açık bir ortama göndermek

12. Başkalarına ait kayıtlı dosyalara izinsiz ulaşmak

13. İnternet aracılığıyla diğer kullanıcıların bilgisayarlarına saldırıda bulunmak

$1.03 \quad 0.22$

14. Kasıtlı olarak virüs göndermek

15. Maddi çıkar ve reklam amaçlı zincir e-posta göndermek

16. Sipariş üzerine hazırlanan bir siteye site sahibinin isteği dışında gizli bağ-

$1.03 \quad 0.16$ lant ve içerik eklemek

17. Başkalarına ait kimlik bilgilerini silmeye çalışmak

18. Özel bilgileri ele geçirmeye yarayan yazııımları ağ üzerinden gönderip yaymak

19. Başkalarının geliştirdiği yazılımları küçük değişikliklerle kendininmiş gibi göstermek

20. Başkalarına ait yayınları kaynak göstermeden kendininmiş gibi kullanmak

21. Sanal topluluklara üye olurken kendini doğru ve olduğu gibi tanıtmamak

22. Başkalarının e-posta şifrelerini ele geçirmeye çalışmak

$1.05 \quad 0.30$

23. Başkalarının web sitelerini çökertmeye çalışmak

$1.06 \quad 0.28$

24. Internet üzerinden kişilere zarar veren propaganda yapmak

25. Yazılım lisanslarını internet üzerinden yayımlamak

26. Programlar kullanarak internet üzerinden oynanan oyunlarda hile yapmak

$1.22 \quad 0.75$

27. Uydu aracılığıyla dosya transferi yapan veri kanallarına gizlice sızarak yüksek hızda dosya indirmek

28. Şifre ile korunan internet ağlarının kullanıcı adı ve şifrelerini ele geçirip izinsiz olarak internete bağlanmak

$1.21 \quad 0.24$

Ölçekteki maddeleri Tablo 2'de yer alan ölçek genel ortalama ( = 1.21) ve standart sapma ( $S S=0.24$ ) değerleri göz önünde bulundurularak incelenmiştir. Bu verilere göre başkalarına ait kimlik bilgilerini silmeye çalışmak ( $=1.02)$ en düşük puan ortalamasına sahip maddedir. Internet üzerinden müzik dosyaları indirmek, çoğaltmak ve dağıtmak ( =2.76), ödev hazırlayan sitelere ödev yaptırmak ( =1.74) maddeleri ise en yüksek puan ortalamasına sahip maddelerdir. Puanın artması etik dışı kullanımın artı̆ını gösterirken puanın azalması etik dışı kullanımın azaldığını göstermektedir.

\section{2. Öğretmen Adaylarının Bilişim Teknolojilerini Etik Kullanım Düzeylerinin Cinsiyete Göre Farklılaşma Durumu}

Bu araştırmanın ikinci araştırma sorusu "Öğretmen adaylarının bilişim teknolojilerini etik kullanım düzeyleri cinsiyete göre farklılaşmakta mıdır?" şeklinde belirlenmiştir. 
Tablo 3. Bilişim Teknolojilerini Etik Kullanım Düzeylerinin Cinsiyete Göre Karşılaştirılması

\begin{tabular}{|l|c|c|c|c|c|c|c|}
\hline Gruplar & $\mathrm{n}$ & $\overline{\mathbf{X}}$ & $\mathrm{SS}$ & $\mathrm{t}$ & $\mathrm{p}$ & $\mathrm{Sd}$ & $\mathrm{d}$ \\
\hline Kadın & 167 & 1.19 & 0.21 & 2.32 & 0.02 & 219 & 0.34 \\
\hline Erkek & 54 & 1.28 & 0.32 & & & & \\
\hline
\end{tabular}

Tablo 3'te yer alan öğretmen adaylarının bilişim teknolojilerini etik kullanım düzeylerinin cinsiyete göre değişip değişmediğinin belirlenmesi amacıyla yapılan bağımsız örneklemler için t testi sonucunda kadınların ortalamasının ( =1.19), erkeklerin ortalamasından ( =1.28) anlamlı olarak daha düşük olduğu belirlenmiştir $(p<0.05)$. Hesaplanan etki büyüklüğü $(d=0.34)$ farkın orta düzeyde olduğunu göstermektedir. Bu bağlamda kadın öğretmen adaylarının erkek öğretmen adaylarına göre bilişim teknolojilerini etik kullanım düzeyleri daha yüksektir.

\section{3. Öğretmen Adaylarının Bilişim Teknolojilerini Etik Kullanım Düzeylerinin Yaşa Göre Farklılaşma Durumu}

Bu araştırmanın üçüncü araştırma sorusu "Öğretmen adaylarının bilişim teknolojilerini etik kullanım düzeyleri yaşa göre farklılaşmakta mıdır?" şeklinde belirlenmiştir.

Tablo 4. Bilişim Teknolojilerini Etik Kullanım Düzeylerinin Yaşa Göre Karşılaştırılması

\begin{tabular}{|l|c|c|c|c|c|}
\hline Yaş Aralı̆̆ı & $n$ & Sıra Ortalamaları & $x^{2}$ & Sd & $p$ \\
\hline (1) $17-19$ & 16 & 121.97 & & & \\
\hline (2) $20-22$ & 159 & 109.04 & & & \\
\hline (3) $23-25$ & 31 & 103.45 & 3.35 & 3 & 0.34 \\
\hline (4) 25 ve üstü & 15 & 135.67 & & & \\
\hline
\end{tabular}

Tablo 4'te yer alan öğretmen adaylarının bilişim teknolojilerini etik kullanım düzeylerinin yaşa göre değişip değişmediğinin belirlenmesi amacıyla yapılan Kruskal-Wallis $\mathrm{H}$ testi sonucunda öğretmen adaylarının bilişim teknolojilerini etik kullanım düzeylerinin yaşa göre istatistiksel olarak anlamlı bir farklılık göstermediği tespit edilmiştir ( $p>0.05$ ).

\section{4. Öğretmen Adaylarının Bilişim Teknolojilerini Etik Kullanım Düzeylerinin Bö- lüme Göre Farklılaşma Durumu}

Bu araştırmanın dördüncü araştırma sorusu “Öğretmen adaylarının bilişim teknolojilerini etik kullanım düzeyleri bölüme göre farklılaşmakta mıdır?" şeklinde belirlenmiştir. 
Tablo 5. Bilişim Teknolojilerini Etik Kullanım Düzeylerinin Bölüme Göre Karşılaştrilması

\begin{tabular}{|c|c|c|c|c|c|}
\hline Bölümler & $\mathrm{n}$ & Sıra Ortalamaları & $x^{2}$ & Sd & $\mathrm{p}$ \\
\hline (1) ВÖTE* & 21 & 151.86 & \multirow{6}{*}{13.39} & \multirow{6}{*}{5} & \multirow{6}{*}{0.02} \\
\hline (2) Fen Bilgisi Öğretmenliği & 51 & 101.60 & & & \\
\hline (3) Sınıf Öğretmenliği & 65 & 108.44 & & & \\
\hline (4) Türkçe Öğretmenliği & 41 & 100.71 & & & \\
\hline (5) Sosyal Bilgiler Öğretmenliği & 22 & 102.32 & & & \\
\hline (6) İlköğretim Matematik Öğretmenliği & 21 & 130.10 & & & \\
\hline
\end{tabular}

Tablo 5'te yer alan öğretmen adaylarının bilişim teknolojilerini etik kullanım düzeylerinin bölüme göre değişip değişmediğinin belirlenmesi amacıyla yapılan Kruskal-Wallis $\mathrm{H}$ testi sonucunda öğretmen adaylarının bilişim teknolojilerini etik kullanım düzeylerinin bölüme göre istatistiksel olarak anlamlı bir farklılık gösterdiği tespit edilmiştir ( $x 2=13.39, p<0.05)$. Bu anlamlı farkın hangi gruplar arasında olduğunu belirlemek için yapılan Post HOC (LSD) testi sonucunda farkın; "BÖTE Fen Bilgisi Öğretmenliği”, “BÖTE - Sınıf Öğretmenliği”, "BÖTE - Türkçe Öğretmenliği”, "BÖTE - Sosyal Bilgiler Öğretmenliği” bölümleri arasında olduğu belirlenmiştir. BÖTE bölümünde öğrenim gören öğretmen adaylarının bilişim teknolojilerini etik kullanım düzeyleri Fen Bilgisi, Sınıf, Türkçe ve Sosyal Bilgiler Öğretmenliği bölümlerinde öğrenim gören öğretmen adaylarına göre daha düşüktür.

\section{5. Öğretmen Adaylarının Bilişim Teknolojilerini Etik Kullanım Düzeylerinin İn- ternet Kullanma Sıklığına Göre Farklılaşma Durumu}

Bu araştırmanın beşinci araştırma sorusu "Öğretmen adaylarının bilişim teknolojilerini etik kullanım düzeyleri internet kullanma sıklığına göre farklılaşmakta mıdır?" şeklinde belirlenmiştir.

Tablo 6. Bilişim Teknolojilerini Etik Kullanım Düzeylerinin İnternet Kullanma Sıklığına Göre Karşılaştrıılması

\begin{tabular}{|l|c|c|c|c|c|}
\hline Internet Kullanma Sıklığı & $\mathrm{n}$ & $\overline{\mathbf{X}}$ & SS & $\mathrm{F}$ & $\mathrm{p}$ \\
\hline (1) $1-3$ saat & 78 & 1.46 & 1.11 & & \\
\hdashline (2) 4-6 saat & 89 & 1.43 & 0.91 & \multirow{2}{*}{1.94} & 0.12 \\
\hline (3) 7-9 saat & 41 & 1.48 & 0.97 & & \\
\hdashline (4) 10 ve üzeri & 13 & 1.77 & 0.67 & & \\
\hline
\end{tabular}


Öğretmen adaylarının internet kullanma sıklığı günlük internet kullanım süresi üzerinden ele alınmıştır. Tablo 6'da yer alan öğretmen adaylarının bilişim teknolojilerini etik kullanım düzeylerinin internet kullanma sıklığına göre değişip değişmediğinin belirlenmesi amacıyla yapılan tek yönlü varyans analizi (ANOVA) sonucunda öğretmen adaylarının bilişim teknolojilerini etik kullanım düzeylerinin internet kullanma sıklığına göre istatistiksel olarak anlamlı bir farklılık göstermediği tespit edilmiştir ( $F=1.94, p>0.05$ ).

\section{6. Öğretmen Adaylarının Bilişim Teknolojilerini Etik Kullanım Düzeylerinin İn- ternet Kullanma Becerisine Göre Farklılaşma Durumu}

Bu araştırmanın altıncı araştırma sorusu “Öğretmen adaylarının bilişim teknolojilerini etik kullanım düzeyleri internet kullanma becerisine göre farklılaşmakta mıdır?" şeklinde belirlenmiştir.

Tablo 7. Bilişim Teknolojilerini Etik Kullanım Düzeylerinin Internet Kullanma Becerisine Göre Karşılaştırılması

\begin{tabular}{|l|c|c|c|c|c|}
\hline Internet Kullanma Becerisi & $\mathrm{n}$ & Sıra Ortalamaları & $\mathrm{x}^{2}$ & $\mathrm{Sd}$ & $\mathrm{p}$ \\
\hline (1) Düşük* & 52 & 109.14 & & & \\
\hdashline$(2)$ Orta & 114 & 103.12 & 6.29 & 2 & 0.04 \\
\hline (3) Yüksek & 55 & 129.08 & & & \\
\hline (1=2<3 & & & & & \\
\hline
\end{tabular}

Tablo 7'de yer alan öğretmen adaylarının bilişim teknolojilerini etik kullanım düzeylerinin internet kullanma becerisine göre değişip değişmediğinin belirlenmesi amacıyla yapılan Kruskal-Wallis $\mathrm{H}$ testi sonucunda öğretmen adaylarının bilişim teknolojilerini etik kullanım düzeylerinin internet kullanma becerisine göre istatistiksel olarak anlamlı bir farklılık gösterdiği tespit edilmiştir ( $x 2=6.29, p<0.05)$. Bu anlamlı farkın hangi gruplar arasında olduğunun belirlenmesi için yapılan Post HOC (LSD) testi sonucunda farkın; internet kullanma becerisi orta olanlar ile internet kullanma becerisi yüksek olanlar arasında olduğu belirlenmiştir. İnternet kullanma becerisi yüksek olan öğretmen adaylarının bilişim teknolojilerini etik kullanım düzeyleri, internet kullanma becerisi orta olan öğretmen adaylarına göre daha düşüktür.

3.7. Öğretmen Adaylarının Bilişim Teknolojilerini Etik Kullanım Düzeylerinin Bilişim Etiğine ilişskin Daha Önce Ders, Kurs veya Seminere Katılmalarına Göre Farklılaşma Durumu

Bu araştırmanın yedinci araştırma sorusu “Öğretmen adaylarının bilişim tekno- 
lojilerini etik kullanım düzeyleri bilişim etiğine ilişkin daha önce ders, kurs veya seminere katılma durumuna göre farklılaşmakta mıdır?" şeklinde belirlenmiştir.

Tablo 8. Bilişim Teknolojilerini Etik Kullanım Düzeylerinin Bilişim Etiğine İlişkin Daha Önce Ders, Kurs veya Seminere Katılma Durumuna Göre Karşılaştırılması

\begin{tabular}{|l|c|c|c|c|c|}
\hline $\begin{array}{l}\text { Bilişim etiğine ilişkin daha önce } \\
\text { ders, kurs veya seminere katılma } \\
\text { durumu }\end{array}$ & $\mathrm{n}$ & $\begin{array}{c}\text { Sıra Ortala- } \\
\text { maları }\end{array}$ & $\begin{array}{c}\text { Mann Whitney } \\
\text { U Testi }\end{array}$ & $\mathrm{Z}$ & $\mathrm{p}$ \\
\hline Evet & 92 & 100.36 & 4561.0 & 2.96 & 0.00 \\
\hline Hayır & 129 & 125.92 & 2.00 \\
\hline
\end{tabular}

Tablo 8'de yer alan öğretmen adaylarının bilişim teknolojilerini etik kullanım düzeylerinin bilişim etiğine ilişkin daha önce ders, kurs veya seminere katılma durumuna göre değişip değişmediğinin belirlenmesi amacıyla yapılan Mann Whitney $\mathrm{U}$ testi sonucunda bilişim etiğine ilişkin daha önce ders, kurs veya seminere katılanların sıra ortalamasının (100.36), katılmayanların sıra ortalamasına (125.92) göre anlamlı bir farklılık gösterdiği tespit edilmiştir $(p<0.05)$. Bilişim etiğine ilişkin daha önce ders, kurs veya seminere katılan öğretmen adaylarının bilişim teknolojilerini etik kullanım düzeyleri, katılmayan öğretmen adaylarına göre daha yüksektir.

\section{8. Öğretmen Adaylarının Bilişim Teknolojilerini Etik Kullanım Düzeylerinin Bi- lişim Suçları ve Cezalarına iliş̧kin Bilgi Düzeyine Göre Farklılaşma Durumu}

Bu araştırmanın sekizinci araştırma sorusu “Öğretmen adaylarının bilişim teknolojilerini etik kullanım düzeyleri bilişim suçları ve cezalarına ilişkin bilgi düzeyine göre farklılaşmakta mıdır?" şeklinde belirlenmiştir.

Tablo 9. Bilişim Teknolojilerini Etik Kullanım Düzeylerinin Bilişim Suçları ve Cezalarına İlişkin Bilgi Düzeyine Göre Karşılaştırılması

\begin{tabular}{|l|c|c|c|c|c|}
\hline $\begin{array}{l}\text { Bilişim Suçları ve Cezalarına ilişkin Bilgi } \\
\text { Düzeyi }\end{array}$ & $\mathrm{n}$ & $\begin{array}{c}\text { Sıra Ortala- } \\
\text { maları }\end{array}$ & $\mathrm{x}^{2}$ & $\mathrm{Sd}$ & $\mathrm{p}$ \\
\hline $\begin{array}{l}\text { (1) Düşük * } \\
\text { (2) Orta }\end{array}$ & 89 & 139.50 & & & \\
\hdashline$(3)$ Yüksek & 103 & 108.17 & 6.89 & 2 & 0.03 \\
\hline *1>2>3 & 29 & 104.99 & & & \\
\hline
\end{tabular}

Tablo 9'da yer alan öğretmen adaylarının bilişim teknolojilerini etik kullanım düzeylerinin bilişim suçları ve cezalarına ilişkin bilgi düzeyine göre değişip değişmediğinin belirlenmesi amacıyla yapılan Kruskal-Wallis $\mathrm{H}$ testi sonucunda öğretmen adaylarının bilişim teknolojilerini etik kullanım düzeylerinin bilişim suçları ve ce- 
zalarına ilişkin bilgi düzeyine göre istatistiksel olarak anlamlı bir farklılık gösterdiği tespit edilmiştir $(x 2=6.89, \mathrm{p}<0.05)$. Bu anlamlı farkın hangi gruplar arasında olduğunun belirlenmesi için yapılan Post HOC (LSD) testi sonucunda farkın; bilişim suçları ve cezalarına ilişskin bilgi düzeyi "Düşük ve Orta”, "Düşük ve Yüksek" olanlar arasında olduğu belirlenmiştir. Bilişim suçları ve cezalarına ilişkin bilgi düzeyi "Düşük" olan öğretmen adaylarının bilişim teknolojilerini etik kullanım düzeyleri "Orta" ve "Yüksek" olan öğretmen adaylarına göre daha düşüktür.

\section{Tartişma ve Sonuç}

Dijital ortamlarda bireylerin karşılaştı̆̆ sorunların başında etik dışı davranışlar gelmektedir. Bireylerin birçoğu bilişim teknolojilerini kullanırken bilerek ya da bilmeyerek dijital ortamlarda etik dışı davranışlar sergilemektedirler (Luke, 2018). Bu nedenle bilişim teknolojilerinin etik kullanımı gün geçtikçe önem kazanmaktadır (Wang, Wang ve Wang, 2020). Bu araştırmada, öğretmen adaylarının bilişim teknolojilerini etik kullanım düzeyleri belirlenen bazı değişkenler açısından incelenmiştir. Öğretmen adaylarının bilişim teknolojilerini etik kullanım düzeyleri; cinsiyet, bölüm, internet kullanma becerisi, bilişim etiğine ilişkin daha önce ders, kurs veya seminere katılma durumu, bilişim suçları ve cezalarına ilişkin bilgi düzeyine göre istatistiksel olarak anlamlı bir farlılık göstermekte; yaş, internet kullanma sıklığına göre ise istatistiksel olarak anlamlı bir farlılık göstermemektedir.

Araştırma sonucunda öğretmen adaylarının bilişim teknolojilerini etik kullanım düzeyleri yüksek çıkmıştır. Diğer bir değişle öğretmen adaylarının bilişim teknolojilerini kullanırken düşük düzeyde ( = 1.21) etik dışı davranışlar sergiledikleri sonucuna ulaşılmıştır. Eğitim-öğretim faaliyetlerinin gün geçtikçe dijital ortamlara taşınması öğretmen ve öğrencilerin bu ortamların sunduğu firsatlardan yararlanırken ortaya çıkabilecek etik problemlere de dikkat etmelerini zorunlu kılmaktadır (Claro, Salinas, Cabello-Hutt, San Martín, Preiss, Valenzuela, ve Jara, 2018). Özellikle küçük yaştaki çocuklar bilişim teknolojilerini kullanma davranışlarını çoğunlukla akranlarını, ebeveynlerini ya da öğretmenlerini taklit ederek öğrenmeye çalışırlar. Taklit ettikleri bu davranışların doğru ya da yanlış olduğunu tam olarak bilmediklerinden dolayı sergiledikleri davranışların uygun ve kabul edilebilir olduğunu düşünebilirler (Claro vd., 2018). Ebeveynlerin birçoğunun bilişim teknolojilerinin etik kullanımına ilişkin yeterli bilgi düzeyine sahip olmadıkları dikkate alındığında ebeveynlerin çocuklarına uygun örnek olamadıkları söylenebilir (Ribble, 2015). Bu nedenle öğretmenlerin bilişim teknolojilerini etik kullanım düzeylerinin yüksek olması öğrenciler tarafindan dijital etik ilkelerinin benimsenmesinde daha etkili olacaktır (Kim ve Choi, 2018). 
Araştırmada, kadın öğretmen adaylarının erkek öğretmen adaylarına göre bilişim teknolojilerini etik kullanım düzeylerinin daha yüksek olduğu sonucuna ulaşılmıştır. Erkek öğretmen adayları bilişim teknolojilerini daha çok etik dışı kullanmaktadırlar. Nitekim bilişim teknolojilerinin etik kullanımı ile ilgili yapılan çalışmaların birçoğunda dijital ortamlarda kadınların erkeklerden daha etik davranışlar gösterdikleri sonucuna ulaşılmıştır (Krisanda ve Peslak, 2009; Lau ve Yuen, 2014; Siponen ve Vartiainen, 2005). Erkekler, kadınlara kıyasla lisanssız yazılım kullanma, bilgisayar korsanlığı gibi etik dışı davranışları daha fazla sergilemektedirler (Kim ve Kim, 2015). Aynı zamanda hem lise hem de üniversitedeki erkek öğrencilerin kadın öğrencilere göre bilişim teknolojilerini akademik aşırmacılıkta daha fazla kullandıkları görülmüştür (Jensen, Arnett, Feldman ve Cauffman, 2002). Bu cinsiyet farklılığının olası nedenleri kadınların bilişim teknolojilerine daha yabancı olmalarından dolayı etik davranışlar sergilemeye istekli olması ve erkeklerin ise bilgisayar kullanma becerilerinin daha yüksek olmasından dolayı kötüye kullanma eğilimlerinin daha yüksek olması olabilir (Gnambs, 2021; Lau ve Yuen, 2014).

Bu çalışmada, öğretmen adaylarının bilişim teknolojilerini etik kullanım düzeylerinin yaşa göre farklılık göstermediği sonucuna ulaşılmıştır. Bu durum çalışma grubundaki öğretmen adaylarının ağırlıklı olarak benzer yaş grubunda yoğunlaşmış olmasından kaynaklanmış olabilir. Aynı zamanda çalışma grubundaki öğretmen adayları dijital yerli olarak tanımlanan yaş grubunda yer almaktadır. Dijital yerliler, önceki nesillere göre küçük yaşlardan itibaren bilgiye daha kolay erişim sağlamakta ve daha fazla bilgi tüketicisi olma konumundadırlar. Özellikle genç yaştaki bireyler doğru ile yanlışı ayırt etmek ve doğru kararlar vermek için gerekli bilgi ve deneyime sahip olmadıklarından etik kararlarla karşılaştıklarında riskli bir durum yaşamaktadırlar (Lau ve Yuen, 2014). Bu nedenle dijital yerlilerin bilişim teknolojilerinin etik kullanımı konusunda küçük yaşlardan itibaren bilgi sahibi olmalarının önem arz ettiği söylenebilir (James, Davis, Flores, Francis, Pettingill, Rundle ve Gardner, 2009).

Araştırmada, BÖTE bölümünde öğrenim gören öğretmen adaylarının bilişim teknolojilerini etik kullanım düzeylerinin Fen Bilgisi, Sınıf, Türkçe ve Sosyal Bilgiler Öğretmenliği bölümünde öğrenim gören öğretmen adaylarına göre daha düşük olduğu sonucuna ulaşılmıştır. BÖTE bölümündeki öğretmen adayları bilişim teknolojilerini diğer bölümlere kıyasla etik dışı daha çok kullanmaktadırlar. BÖTE bölümündeki öğrencilerin bilişim teknolojilerinin kullanımı konusundaki yeterliliklerinin daha yüksek olması bu bölümdeki öğrencilerin etik dışı kullanımlarını artırmış olabilir.

Araştırmada, öğretmen adaylarının bilişim teknolojilerini etik kullanım düzeylerinin internet kullanma sıklığına göre farklılık göstermediği sonucuna ulaşılmıştır. Günümüzde bireylerin çok küçük yaşlardan itibaren bilişim teknolojileri ile tanışarak in- 
ternette uzun zaman geçirdikleri göz önüne alınırsa etik problemlerle karşı karşıya kalmaları muhtemeldir. Bu nedenle bireylerin dijital etik ilkelerini benimsemeleri önemlidir.

Bu çalışmada, internet kullanma becerisi yüksek olan öğretmen adaylarının bilişim teknolojilerini etik kullanım düzeylerinin internet kullanma becerisi orta olan öğretmen adaylarınınkine göre daha düşük olduğu sonucuna ulaşılmıştır. Internet kullanma becerisi yüksek olan öğretmen adayları bilişim teknolojilerini daha çok etik dışı kullanmaktadırlar. Yapılan çalışmalarda da benzer olarak internet kullanma becerisi yüksek olan bireylerin bilişim teknolojileri daha çok etik dışı kullandıkları sonucuna ulaşılmıştır (Beyhan ve Tunç, 2012; Kumazaki, Suzuki, Katsura, Sakamoto ve Kashibuchi, 2011; Livingstone ve Helsper, 2010). Internetin bilgiye ulaşmada sağladığı firsatlar ve bilginin anonimliğinin artması etik dışı davranışların sıradanlaşması algısını artırmaktadır (Freestone ve Mitchell, 2004).

Araştırmada, bilişim etiğine ilişkin daha önce ders, kurs veya seminere katılan öğretmen adaylarının bilişim teknolojilerini etik kullanım düzeylerinin katılmayan öğretmen adaylarınınkine göre daha yüksek olduğu sonucuna ulaşılmıştır. Eğitim alan öğretmen adayları bilişim teknolojilerini daha az etik dışı kullanmaktadırlar. Bilişim teknolojilerinin kullanımı konusunda ortaya çıkan problemler, bireylerin beceri veya teknolojik yeterliklerinden değil daha çok etik dışı kullanımından kaynaklanmaktadır. Dijital etik bu nedenle eğitim müfredatının temel meselesi olarak değerlendirilebilir (Luke, 2018). Dijital etik konusundaki eğitim sadece öğretmen eğitiminde değil genel olarak okullarda da bir eksikliktir (Pérez-Garcias ve Marín, 2016). Bu doğrultuda bilişim teknolojilerinin kullanımında etik konuların göz önünde bulundurulmasının ve öğretmenlerin dijital etik konusundaki bilgi ve davranışlarının geliştirilmesinin gerekli olduğu düşünülmektedir. Yapılan çalışmalar dijital ortamlara ilişkin etik eğitimi verilmesinin bilişim teknolojilerinin etik kullanımına yönelik tutum geliştirilmesinde pozitif yönde bir etki sağladığını göstermektedir (Leonard, Cronan ve Kreie, 2004; Pérez-Garcias ve Marín, 2016; Wang, Wang ve Wang, 2020). Etik eğitimi ile ilgi yapılan çalışmalar da benzer olarak etik eğitimi ile kişinin etik yargıları arasında önemli bir ilişki olduğunu göstermektedir (Earley ve Kelly, 2004; Lau 2010; Shapiro ve Stefkovich, 2016).

Bu araştırmada, bilişim suçları ve cezalarına ilişkin bilgi düzeyi "Düşük" olan öğretmen adaylarının bilişim teknolojilerini etik kullanım düzeylerinin "Orta" ve "Yüksek" olan öğretmen adaylarınınkine göre daha düşük olduğu sonucuna ulaşılmıştır. Bilişim suçları ve cezalarına ilişkin bilgi düzeyi düşük olan öğretmen adayları bilişim teknolojilerini daha çok etik dışı kullanmaktadırlar. Bilişim teknolojilerini kullanırken etik dışı davranışlar sergilemenin nedenlerinden biri de bilişim suçları ve ceza- 
larına ilişkin yeterli bilgiye sahip olunmamasıdır. Suç işleyen kişinin yol açtı̆̆ zararı veya zarara uğrayan tarafi görmemesi herhangi bir olumsuzluk yaşamayacağına ilişkin bir algı yaratmaktadır (Freestone ve Mitchell, 2004).

Öneriler:

Bu çalışmadan elde edilen bulgular bağlamına uygulamaya ve gelecek araştırmalara yönelik aşağıdaki önerilerde bulunulabilir. BÖTE bölümünde öğrenim gören öğretmen adaylarının bilişim teknolojilerini etik kullanım düzeylerinin diğer bölümlerde öğrenim gören öğretmen adaylarına göre daha düşük çıkmasının nedenleri araştırılabilir.

Internet kullanma becerisi yüksek olan öğretmen adaylarının bilişim teknolojilerini etik dışı kullanma nedenleri araştırılabilir. Öğretmen adaylarına yönelik bilişim teknolojilerini etik kullanım düzeylerini artıracak, gelecek nesli dijital çağa hazırlamada öğretmenlere önemli sorumluluklar düştüğünü benimsetecek, bilişim suç ve cezaları hakkında bilgi sahibi olmalarını sağlayacak dijital etik ile ilgili kurs, seminer veya konferanslar düzenlenebilir. Araştırmanın genellenebilirliğini artırmak amacıyla benzer araştırma katılımcı sayısı artırılarak tekrarlanabileceği gibi nitel veya karma araştırma yöntemleri kullanılarak da tekrar desenlenebilir.

\section{Kaynakça}

Beyhan, Ö., \& Tunç, H. S. (2012). Öğretmen adayı öğrencilerin bilişim teknolojilerini etik kullanımlarının incelenmesi. Yükseköğretim Dergisi, 2(2), 85-94.

Buchholz, B. A., DeHart, J., \& Moorman, G. (2020). Digital citizenship during a global pandemic: Moving beyond digital literacy. Journal of Adolescent \& Adult Literacy, 64(1), 11-17.

Claro, M., Salinas, Á., Cabello-Hutt, T., San Martín, E., Preiss, D. D., Valenzuela, S., \& Jara, I. (2018). Teaching in a digital environment (TIDE): Defining and measuring teachers' capacity to develop students' digital information and communication skills. Computers \& Education, 121, 162-174.

Chen, L. L., Mirpuri, S., Rao, N., \& Law, N. (2021). Conceptualization and measurement of digital citizenship across disciplines. Educational Research Review, 100379.

Çelen, F. K., \& Seferoğlu, S. S. (2016). Bilgi ve iletişim teknolojilerinin kullanımı ve etik olmayan davranışlar: sorunlar, araştırmalar ve değerlendirmeler. Journal of Computer and Education Research, 4(8), 124-153.

Dedeoğlu, G. (2006). Bilişim toplumu ve etik sorunlar. Bursa: Alfa Aktüel Yayınları.

Earley, C. E., \& Kelly, P. T. (2004). A note on ethics educational interventions in an undergraduate auditing course: Is there an "Enron effect"? Issues in Accounting 
Education, 19(1), 53-71.

Floridi, L. (2001). Ethics in the infosphere. The Philosophers' Magazine, 4(16), 18-19. https://doi.org/10.5840/tpm20011647

Fraenkel, J. R., Wallen, N. E., \& Hyun, H. H. (2011). How to design and evaluate research in education. New York: McGraw-Hill.

Freeman, L., \& Peace, A. G. (2005). Information ethics: Privacy and intellectual property. IGI Global.

Freestone, O., \& Mitchell, V. (2004). Generation $Y$ attitudes towards e-ethics and internet-related misbehaviours. Journal of Business Ethics, 54(2), 121-128.

Friedman, B. (1997). Social judgement and technological innovation: Adolescents' understanding of property, privacy and electronic information. Computers in Human Behavior, 13(3), 327-351. https://doi.org/10.1016/S07475632(97)00013-7

Gazi, Z. A. (2016). Tüm eğitim kademesinin geleceği için dijital vatandaşlığın içselleştirilmesi. Eğitim ve Bilim, 41(186), 137-148. http://dx.doi.org/10.15390/ EB.2016.4533

Gilster, P. (1997). Digital literacy. New York: Wiley Computer Publications.

Gnambs, T. (2021). The development of gender differences in information and communication technology (ICT) literacy in middle adolescence. Computers in Human Behavior, 114, 106533.

Hollandsworth, R., Donovan, J., \& Welch, M. (2017). Digital citizenship: You can't go home again. TechTrends, 61(6), 524-530. https://doi.org/10.1007/s11528-0170190-4

Instefjord, E. J., \& Munthe, E. (2017). Educating digitally competent teachers: A study of integration of professional digital competence in teacher education. Teaching and Teacher Education, 67, 37-45.

International Society for Technology in Education (ISTE) (2016). National education technology standarts for students. International Society for Technology in Education, Washington, DC, ABD. Erişim adresi: http://www.iste.org/standards/for-students adresinden 26 Mart 2021 tarihinde erişilmiştir.

International Society for Technology in Education (ISTE) (2017). National education technology standarts for educators. International Society for Technology in Education, Washington, DC, ABD. Erişim adresi: http://www.iste.org/standards/for-educators adresinden 26 Mart 2021 tarihinde erişilmiştir.

James, C, Davis, K, Flores, A, Francis, J, Pettingill, L, Rundle, M., \& Gardner, H (2009) Young people, ethics, and the new digital media: A synthesis from the GoodPlay Project. The John D. and Catherine T. MacArthur Foundation Reports on Digital Media and Learning. Cambridge, MA: The MIT Press.

Jensen, L. A., Arnett, J. J., Feldman, S. S., \& Cauffman, E. (2002). It's wrong, but everybody does it: Academic dishonesty among high school and college students. Contemporary Educational Psychology, 27(2), 209-228.

Johnson, D. G. \& K. Miller (2009). Computer ethics: Analyzing information technology. Pearson Education International.

Johnson, D. G. (1985). Computer ethics. Prentice-Hall.

Kelentrić, M., Helland, K., \& Arstorp, A. T. (2017). Professional digital competence framework for teachers. The Norwegian Centre for ICT in Education, 1-74. 
Kim, M., \& Choi, D. (2018). Development of youth digital citizenship scale and implication for educational setting. Journal of Educational Technology \& Society, 21(1), 155-171.

Kim, J. E., \& Kim, J. (2015). International note: Teen users' problematic online behavior: Using panel data from South Korea. Journal of Adolescence, 40, 48-53.

Krisanda, J., \& Peslak, A. (2009). The effect of gender on the application of ethics within information technology: A meta-analysis. The proceedings of the conference on information Systems applied research (pp. 1-14). Washington DC.

Kumazaki, A., Suzuki, K., Katsura, R., Sakamoto, A., \& Kashibuchi, M. (2011). The effects of netiquette and ICT skills on school-bullying and cyber-bullying: The two-wave panel study of Japanese elementary, secondary, and high school students. Procedia-Social and Behavioral Sciences, 29, 735-741.

Kuzu, A. (2009). Problems related to computer ethics: Origins of the problems and suggested solutions. Turkish Online Journal of Educational Technology, 8(2), 91-110.

Lau, C. L. (2010). A step forward: Ethics education matters! Journal of Business Ethics, 92(4), 565-584.

Lau, W. W., \& Yuen, A. H. (2014). Internet ethics of adolescents: Understanding demographic differences. Computers \& Education, 72, 378-385.

Leonard, L. N., Cronan, T. P., \& Kreie, J. (2004). What influences IT ethical behavior intentions-planned behavior, reasoned action, perceived importance, or individual characteristics? Information \& Management, 42(1), 143-158.

Livingstone, S., \& Helsper, E. (2010). Balancing opportunities and risks in teenagers' use of the internet: The role of online skills and internet self-efficacy. New Media \& Society, 12(2), 309-329.

Luke, A. (2018). Digital ethics now. Language and Literacy, 20(3), 185-198. https://doi. org/10.20360/langandlit29416

Lund, A., Furberg, A., Bakken, J., \& Engelien, K. L. (2014). What does professional digital competence mean in teacher education?. Nordic Journal of Digital Literacy, 9(04), 280-298.

Marshall, K. P. (1999). Has technology introduced new ethical problems? Journal of Business Ethics, 19(1), 81-90.

Mason, R. O. (1986). Four ethical issues of information age. MIS Quarterly, 10(1), 5-12. https://doi.org/10.2307/248873

Meyers, E. M., Erickson, I., \& Small, R. V. (2013). Digital literacy and informal learning environments: An introduction. Learning, Media and Technology, 38(4), 355-367. https://doi.org/10.1080/17439884.2013.783597

Morgan, K., \& Morgan, M. (2008). Ethical issues in digital information technology. In T. Hansson (Ed.), Handbook of Research on Digital Information Technologies: Innovations, Methods, and Ethical Issues (pp. 455-464). IGI Global. http:// doi:10.4018/978-1-59904-970-0.ch029

Moor, J. H. (1985). What is computer ethics? Metaphilosophy, 16(4), 266-275. https://doi. org/10.1111/j.1467-9973.1985.tb00173.x

Moor, J. H. (2004). Reason, relativity, and responsibility in computer ethics. Readings in CyberEthics (2nd Edition). Jones and Bartlett Publishers. 
Moor, J. H. (2005). Why we need better ethics for emerging technologies. Ethics and Information Technology, 7(3), 111-119. https://doi.org/10.1007/s10676006-0008-0

Mossberger, K., Tolbert, C. J., \& McNeal, R. S. (2007). Digital citizenship. The Internet, society and participation. Cambridge: The MIT Press.

Namlu, A. G., \& Odabaşı, H. F. (2007). Unethical computer using behavior scale: A study of reliability and validity on Turkish university students. Computers \& Education, 48(2), 205-215. https://doi.org/10.1016/j.compedu.2004.12.006

National Telecommunications and Information Administration (NTAI) (1999). Falling through the net: Defining the digital divide. A report on the telecommunications and information technology gap in America. NTAI, Department of Commerce. Erişim adresi: https://www.ntia.doc.gov/legacy/ntiahome/ fttn99/part1.html\#c 20 Mart 2021 tarihinde erişilmiştir.

Pérez Garcias, A., \& Marín, V. I. (2016). Ethics issues of digital contents for pre-service primary teachers: A Gamification Experience for Self-Assessment with Socrative. IAFOR Journal of Education, 4(2), 80-96.

Prensky, M. (2001). Digital natives, digital immigrants. On the Horizon, 9(5), 1-6.

Ribble, M. S., Bailey, G. D., \& Ross, T. W. (2004). Digital citizenship: Addressing appropriate technology behavior. Learning \& Leading with Technology, 32(1), 6-11.

Ribble, M. (2015). Digital citizenship in schools: Nine elements all students should know. International Society for Technology in Education.

Shapiro, J. P., \& Stefkovich, J. A. (2016). Ethical leadership and decision making in education: Applying theoretical perspectives to complex dilemmas. Routledge.

Siponen, M. T., \& Vartiainen, T. (2005). Attitudes to and factors affecting unauthorized copying of computer software in Finland. Behaviour \& Information Technology, 24(4), 249-257.

Sivin, J. P., \& Bialo, E. R. (1992). Ethical use of information technologies in education: Important issues for America's schools. Washington, DC: National Institute of Justice.

Snyder, L. (2012). Fluency with information technology: Skills, concepts \& capabilities (5th Edition). Addison Wesley.

Torun, E. D. (2014). Bilgi ve iletişim teknolojileri kullanımında etik olmayan davranışların modellenmesi. Erciyes İletişim Dergisi, 3(3), 56-70.

TÜiK (2020). Hane halkı bilişim teknolojileri kullanım araştırması, 2020. Türkiye İstatistik Enstitüsü, Ankara. Erişim adresi: http://www.tuik.gov.tr/PreHaberBultenleri.do?id=33679 adresinden 30 Mart 2021 tarihinde erişilmiştir.

Wang, Y. Y., Wang, Y. S., \& Wang, Y. M. (2020). What drives students' Internet ethical behaviour: An integrated model of the theory of planned behaviour, personality, and Internet ethics education. Behaviour \& Information Technology, 1-23. 